Luke Brander, Florian Eppink, Jan Philipp Schägner, Pieter van

Beukering, Alfred Wagtendonk

\title{
GIS-Based Mapping of Ecosystem Services: The Case of Coral Reefs
}

Chapter in book | Accepted manuscript (Postprint)

This version is available at https://doi.org/10.14279/depositonce-8672

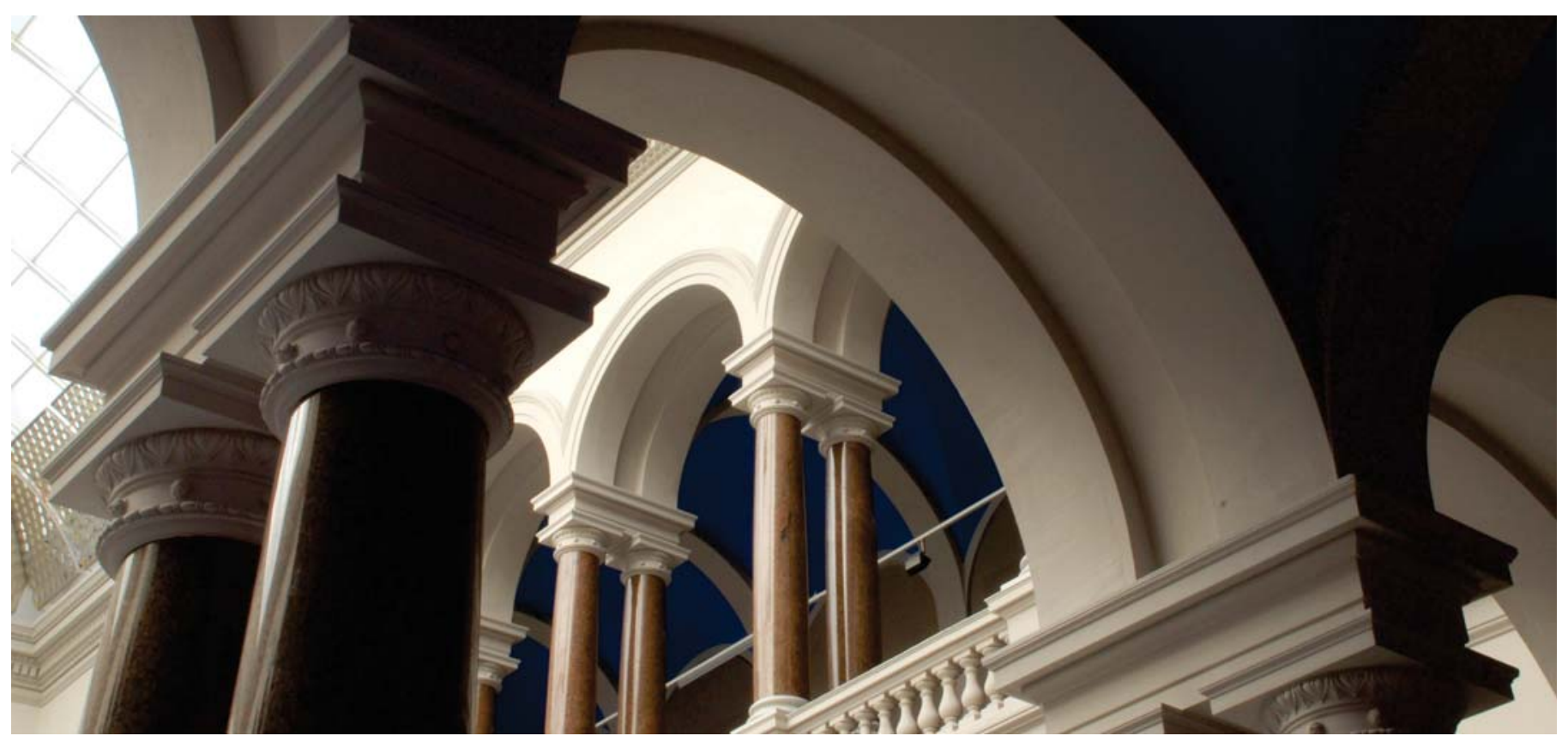

Brander L.M., Eppink F.V., Schägner P., van Beukering P.J.H., Wagtendonk A. (2015) GIS-Based Mapping of Ecosystem Services: The Case of Coral Reefs. In: J ohnston R., Rolfe J., Rosenberger R., Brouwer R. (eds) Benefit Transfer of Environmental and Resource Values. The Economics of Non-Market Goods and Resources, vol 14. Springer, Dordrecht. (pp. 465-485). https://doi.org/10.1007/978-94-017-9930-0_20 


\title{
GIS-Based Mapping of Ecosystem Services: The Case of Coral Reefs
}

Luke Brander $^{\text {ab }}$, Florian Eppink ${ }^{c}$, Jan Philipp Schägner ${ }^{d}$, Pieter van Beukering ${ }^{a}$, Alfred Wagtendonk ${ }^{a}$

\section{Keywords:}

Value mapping

GIS

Meta-analysis

Coral reefs

Recreation

\begin{abstract}
This chapter illustrates the process of mapping ecosystem service values with an application to coral reef recreational values in Southeast Asia. The case study provides an estimate of the value of reefrelated recreation foregone, due to the decline in coral reef area in Southeast Asia, under a baseline scenario for the period $2000-2050$. This value is estimated by combining a visitor model, metaanalytic value function and spatial data on individual coral reef ecosystems to produce site-specific values. Values are mapped in order to communicate the spatial variability in the value of coral reef degradation. Although the aggregated change in the value of reef-related recreation due to ecosystem degradation is not high, there is substantial spatial variation in welfare losses, which is potentially useful information for targeting conservation efforts.
\end{abstract}

${ }^{a}$ Vrije Universiteit, Amsterdam, The Netherlands; ${ }^{b} \mathrm{~L}$; Kadoorie Institute, University of Hong Kong, Pokfulam, Hong Kong; 'Landcare Research, Auckland, New Zealand; dDepartment of Landscape Architecture and Environmental Planning, Technical University Berlin, Berlin, Germany

Published in: 2015. Benefit Transfer of Environmental and Resource Values, edited by Robert J. Johnston, John Rolfe, Randall S. Rosenberger, and Roy Brouwer, 465-85. The Economics of NonMarket Goods and Resources 14. Springer Netherlands.

https://doi.org/10.1007/978-94-017-9930-0 20 


\section{Introduction}

The framework of ecosystem services (ESS) is widely used for understanding and communicating the links between ecosystems and human well-being (MA 2005). Many studies aim to integrate ESS assessments into decision-making processes (TEEB 2010; UK NEA 2011). The economic value (i.e., contribution to human welfare) of an ESS is, as with any good or service, determined by its supply and demand. The supply side of an ESS is largely determined by ecological processes and characteristics (e.g., functioning, fragmentation, productivity, resilience or climate) that may be influenced by human activities, either deliberately or inadvertently. The understanding and modelling of the supply of ESS has largely been taken up by natural scientists (e.g., ecologists, geographers, hydrologists). The demand side of an ESS is largely determined by the characteristics of human beneficiaries of the ESS (population, preferences, distance to the resource, etc.) and modelling hereof has largely been taken up by economists. It has been recognized that the determinants of both the supply and demand of ESS are spatially variable, which makes the assessment of ESS values inherently a spatial analysis. In recent years, a growing body of literature has assessed ESS spatially by producing digital maps either of ESS supply or its value. With the development of advanced GIS technology, mapping of ESS values has emerged and become an important research issue, in particular the mapping of monetary values for ESS value (Bateman et al. 1999; Brainard 1999; Maes et al. 2013; Schägner et al. 2013; Troy and Wilson 2006). This literature therefore includes studies that produce graphical value maps as well as analyses that explicitly address spatial variability in values.

We define mapping of ESS values as the valuation of ESS in monetary terms across a relatively large geographical area that includes the examination of how values vary across space. Thereby, mapping of ESS values reveals additional information as compared to traditional site-specific ESS valuation, which is beneficial for designing spatially efficient policies and institutions for maintaining ESS supply. Most often, this mapping involves some type of benefit transfer, in which values from one set of locations are used to project or approximate values in other areas.

To some extent, spatial issues have been disregarded in environmental and resource economics, including ESS valuation, but have attracted increasing attention with the emergence of advanced GIS technology in the 1990s (Bockstael 1996). The first studies to map ESS values examined recreational values for Welsh forests (Bateman et al. 1995) and multiple ESS across a protected area in Belize (Eade and Moran 1996). Since then, the number of publications mapping ESS values has grown exponentially. Schägner et al. (2013) provide a review of the literature on mapping ESS values and show that almost $60 \%$ of such studies have been published after 2007 . The methodologies applied in these studies differ widely, particularly with respect to how spatial variation in ESS values is estimated. The precision and accuracy of mapped ESS values have been questioned, and accordingly the utility for policy guidance. However, no consensus has been reached on which methods can and should be used to inform specific policy contexts (de Groot et al. 2010).

The purpose of this chapter is to develop and apply a method for mapping the value of the recreational use of ecosystems, based on a meta-analytic benefit function transfer. The chapter is organized as follows: Sect. 5.2 describes the methods that have been applied in the literature so far. Section 5.3 describes an application of value mapping to assess the welfare loss associated with coral reef degradation in Southeast Asia under a business-as-usual scenario for the period $2000-2050$. This section contains details on the case study region, methodology, visitor model, meta-analytic value function, scenario for coral reef degradation and value maps. Section 5.4 provides conclusions on the results, methods and avenues for future research. 


\section{Methodologies for Mapping Ecosystem Service Values}

The estimation of accurate ESS values requires that models account for spatial heterogeneity in biophysical and socioeconomic conditions. The spatial perspective of variation in ESS values is relatively new and has not been extensively researched (Schaafsma et al. 2012). Insufficient knowledge exists about how ESS values differ across space and the spatial determinants of these values (Bateman et al. 2002; Bockstael 1996; de Groot et al. 2010; Plummer 2009; Schaafsma et al. 2013). Spatial factors that affect the supply of ecosystem services include, among others: ecosystem area (possibly characterized by a non-linear relationship and/or with thresholds), networks, fragmentation, and biodiversity. Spatial factors that affect demand for ecosystem services include: the number of beneficiaries, distance to the ecosystem, availability of substitutes, complements, and accessibility. See Bateman et al. (2002) and Hein et al. (2006) for more detailed discussions of spatial determinants of ecosystem service demand and supply.

Besides communication and visualization, value mapping makes site-specific ecosystem service values available on a large spatial scale. It allows decision makers to extract estimated values from a map or database for the locations or areas of policy interest in order to evaluate potential policy measures. New time-consuming primary valuation studies may therefore not be necessary.

Spatially explicit ESS value maps have specific advantages for several types of policy applications including green accounting, land use policy evaluation, resource allocation and payments for ES. Green accounting includes information on environmental goods and services and/or natural capital in national accounts. Mapping of ESS values allows the estimation of values at different spatial scales, and the aggregation of total ESS values across the region of interest for inclusion in green accounts (TEEB 2010). For land use policy evaluation, the mapping of ESS values allows for the evaluation of broad land use policies at a regional or even supranational level. Typically, land uses are multifunctional and therefore provide multiple services. ESS value mapping displays the trade-offs and synergies in ESS values that may result from land use change. For improving resource allocation, the mapping of ESS values not only supports decisions on whether or not to implement a policy measure, it also informs where to implement a policy measure. It allows the identification of locations in order to minimize negative or maximize positive impacts on the provision of ecosystem service (Naidoo et al. 2008; Polasky et al. 2008). Regarding payments for ES, by making ESS values spatially explicit, schemes can be designed to allow for more efficient and cost-effective incentives across providers. The levels of payments can then be more closely related to the value of services provided by different locations.

Methodologies used for mapping ecosystem service supply can be divided into five main categories (Eigenbrod et al. 2010; Schägner et al. 2013): (1) one-dimensional proxies for ecosystem services, such as land cover or land use (e.g., Costanza et al. 1997; Helian et al. 2011; Simonit and Perrings 2011); (2) non-validated models: ecological production functions based on likely causal combinations of explanatory variables, which are grounded in researcher or expert assumptions (e.g., Holzkämper and Seppelt 2007; Naidoo and Adamowicz 2005; Zhang et al. 2011); (3) validated models: ecological production functions, which are calibrated based on primary or secondary data on ecosystem service supply (e.g., Coiner et al. 2001; Mashayekhi et al. 2010); (4) representative samples of the study area: data on ecosystem service supply that is collected for the specific study area (e.g., Chen et al. 2009; Crossman et al. 2010); and (5) implicit modelling of ecosystem service supply within a value transfer function, i.e., the quantity of ecosystem service supply is modelled within the valuation of the ecosystem service using variables that capture supply-side factors (e.g., Brander et al. 2012; Costanza et al. 2008). 


\section{Application: Mapping Coral Reef Values in Southeast Asia}

This section provides an illustration of the process of mapping ecosystem services values in an application to value changes in coral reef recreational values in Southeast Asia. The purpose of this case study is to illustrate the data, methods and results of a value mapping exercise.

\subsection{Coral Reef Recreation, Threats and Values in Southeast Asia}

Southeast Asia has the most extensive and diverse coral reefs in the world. They cover approximately $70,000 \mathrm{~km}^{2}$, which is $28 \%$ of the global total area of coral reef (Burke et al. 2011). Within the region, the Coral Triangle, which includes the reefs of Indonesia, the Philippines and Malaysia, contains $76 \%$ of all known coral species and hosts $37 \%$ of all known coral reef fish species. The coral reefs of Southeast Asia are highly productive ecosystems that provide a variety of valuable ecosystem services to local populations (Burke et al. 2011; UNEP 2006). These ecosystem services include coastal protection, habitat and nursery functions for commercial and subsistence fisheries, recreational and tourism opportunities, and the existence of diverse natural ecosystems. In this case study we focus on the recreational and tourism uses of coral reefs.

Tourism is one of the largest and fastest growing industries in the world. In Southeast Asia, tourism accounted for $11.1 \%$ of the region's GDP in 2012 and is forecast to grow at 5.8\% per annum over the coming decade (WTTC 2013). Reef-related tourism is expected to increase even more rapidly (Musa and Dimmock 2012). Recreational activities associated with coral reefs include diving, snorkelling, viewing from boats, and fishing. In addition, many beaches are protected by reefs or formed from coral material. Cesar et al. (2003) estimate the total global annual value of coral reef-based recreation and tourism at US\$ 9.6 billion.

Given the range and serious nature of threats to the ecological integrity of coral reefs, there is a need for more information on the value of welfare losses associated with a decline in the provision of ecosystem services (MA 2005). Information on the value of coral reef ecosystem services can be used in a number of different policy-making contexts, including the justification for establishing marine protected areas, determination of compensation payments for damage to coral reefs, setting of user fees for access to protected areas, cost-benefit analysis of conservation and restoration measures, and advocacy regarding the economic importance of properly functioning marine ecosystems (Van Beukering et al. 2007).

\subsection{Outline of the Case Study Methodology}

The aim of this case study is to provide an estimate of the loss in value of coral reef-related recreation resulting from the decline in coral reef area under a business-as-usual scenario for the period 2000 2050. In other words, it estimates one component of the cost of policy inaction from not adequately addressing the multiple threats facing coral reefs in the region. The changes in coral reef-related recreation values are mapped in order to account for spatial variation in the determinants of value and present the results in a spatially explicit way, allowing for the identification of high impact locations. Following Sen et al. (2014), the selected methodology uses a combination of a validated model for visits to coral reefs and a meta-analytic value function to estimate the value per visit. An alternative approach would be to use a meta-analysis to estimate recreational values on a per hectare basis and implicitly model the number of visits to each hectare of an ecosystem within the value function. This is the approach used, for example, by Ghermandi and Nunes (2013) for estimating the recreational value of the world's coasts. Due to data limitations on recreational visit flows at a global scale with which to estimate a model of visits, they transfer values on a per hectare basis rather than per recreational visit. 
The methodology involves the following steps:

1. Estimate a model of recreational visits to individual coral reef sites. The visitor model relates the number of visits per day to the site and context characteristics of each coral reef ecosystem such as degree of siltation or fishing damage.

2. Estimate a value function for coral reef recreation through a meta-analysis of existing monetary estimates. The value function relates the value per visitor day to the characteristics of the ecosystem and its surroundings.

3. Develop a database of coral reef ecosystems in Southeast Asia containing information on the variables included in the visitor model and value function estimated in steps 1 and 2 .

4. Develop a baseline scenario for the change in the quality and spatial extent of coral reef ecosystems in Southeast Asia for the period 2000 - 2050. This baseline scenario is spatially variable to reflect variation in location-specific pressures on coral reef ecosystems.

5. Combine the models and data generated in steps 1 through 4 to produce estimates of the value of the loss in coral reef-related recreation under the baseline scenario. This approach allows the estimation of spatially variable, site-specific values that reflect the characteristics and context (e.g., pressure or threat) of each coral reef.

\subsection{Visitor Model}

In the first step of the analysis, we estimate a visitor model which explains variation in the number of visits by individual visitors to a given coral reef site per day. This is modelled as a function of several explanatory variables describing the characteristics of the ecosystem and its surroundings. We estimate the visitor model using a large sample survey for coral reef sites in Southeast Asia. ${ }^{1}$ These data have a panel structure in that multiple observations of visitor numbers are taken for the same coral reef site at different points in time. Using a GIS, the visitor data are combined with additional information on spatially referenced variables obtained from multiple sources (including area of other ecosystems, population and economic activity in the vicinity of each coral reef site).

\footnotetext{
${ }^{1}$ Reef Check is a volunteer survey program that has collected biophysical and visitor data at reef sites for more than 3000 survey sites in 80 countries globally since 1997 (see: www.reefcheck.org).
} 
Table 1: Variables included in the visitor model for Southeast Asia.

\begin{tabular}{l|l|l|l}
\hline Variable & Variable definition & Mean & Standard deviation \\
\hline Visitors & Number of visitors per day & 16.216 & 15.396 \\
\hline Siltation & Dummy: 1 = siltation; 0 = none & 0.717 & 0.451 \\
\hline Fishing damage & Dummy: 1 = fishing damage; 0 = none & 0.290 & 0.454 \\
\hline Air temperature & Average air temperature (oC) & 30.795 & 1.751 \\
\hline Area of coral cover & Area of coral cover $\left(\mathrm{km}^{2}\right)$ & 11.351 & 38.553 \\
\hline Area of mangroves & Area of mangroves within $50 \mathrm{~km}\left(\mathrm{~km}^{2}\right)$ & 32.298 & 79.124 \\
\hline Population & Population within $50 \mathrm{~km}$ & 739,273 & 920,681 \\
\hline GCP & Gross cell product within $50 \mathrm{~km}(\mathrm{US} \$)$ & 6732 & 4533 \\
\hline
\end{tabular}

The dependent variable in the estimated regression model $(\gamma)$ is the number of visitors per day to a specific reef location. The explanatory variables are grouped in two matrices that include the site characteristics in $X s$ and context characteristics in $X c$. Table 1 presents the list of variables included in the analysis with the mean and standard deviation of each.

The model fit was considerably improved, and heteroskedasticity mitigated, by using the natural logarithms of the area and context variables. Following Bateman and Jones (2003), Brander et al. (2007), and Brouwer et al. (1999), we use a multilevel modelling (MLM) approach to estimate the meta-regression. ${ }^{2}$ MLM allows a relaxation of the common assumption of independent observations, and enables us to examine hierarchies within the data, such as similarity of observations for the same reef. The use of MLM provides an indication of where the assumption of independence may be invalid, and also improves the estimation of standard errors on parameter coefficients. The estimated model is given in following equation:

$$
\gamma_{i j}=\alpha+\beta s X s_{i j}+\beta c X c_{i j}+\mu_{j}+e_{i j}
$$

where the subscript $i$ takes values from 1 to the number of observations of visits and subscript $j$ takes values from 1 to the number of reefs. $\alpha$ is the constant term, $\mu_{j}$ is a vector of residuals at the second (reef) level, $e_{i j}$ is a vector of residuals at the first (observation) level, and the vectors $\beta$ contain the estimated coefficients on the respective explanatory variables. In this equation, both $\mu_{j}$ and $e_{i j}$ are random quantities with means equal to zero. We assume that these variables are uncorrelated and also that they follow a Normal distribution so that it is sufficient to estimate their variances, $\sigma_{\mu}^{2}$ and $\sigma_{e}^{2}$ respectively (Rasbash et al. 2003). This type of model is also known as an error variance components model, given that the residual variance is partitioned into components corresponding to each level in the hierarchy. In our model, the level 2 residuals represent each reef's departure from the population mean, represented by the constant term, and the level 1 residuals reflect the conventional error variance at observation level. The estimated regression model is presented in Table 2 .

\footnotetext{
${ }^{2}$ The software used is MLwiN version 2.0 (see Rasbash et al. 2003).
} 
Table 2: Estimated visitor model for Southeast Asia

\begin{tabular}{|c|c|c|c|}
\hline Variable & Variable definition & Coefficient & $\begin{array}{l}\text { Standard } \\
\text { error }\end{array}$ \\
\hline Constant & - & $-37.301^{* *}$ & 16.073 \\
\hline Siltation & Dummy: 1 = siltation; 0 = none & $-5.866 * * *$ & 0.932 \\
\hline $\begin{array}{l}\text { Dynamite fishing } \\
\text { damage }\end{array}$ & Dummy: 1 = fishing damage; 0 = none & $-7.036 * * *$ & 1.212 \\
\hline Air temperature & Air temperature $\left({ }^{\circ} \mathrm{C}\right)$ & $-0.569 * * *$ & 0.162 \\
\hline Area of coral cover & Natural log of area of coral cover $\left(\mathrm{km}^{2}\right)$ & 1.027 & 0.638 \\
\hline Area of mangroves & $\begin{array}{l}\text { Natural log of area of mangroves } \\
\text { within } 50 \mathrm{~km}\left(\mathrm{~km}^{2}\right)\end{array}$ & $0.685^{*}$ & 0.373 \\
\hline Population & Natural log of population within $50 \mathrm{~km}$ & $-0.886^{*}$ & 0.467 \\
\hline GCP & $\begin{array}{l}\text { Natural log of Gross Cell Product } \\
\text { within } 50 \mathrm{~km} \text { (US\$) }\end{array}$ & $9.672 * * *$ & 1.373 \\
\hline \multicolumn{2}{|c|}{ Level 1 (observation) variance } & $145.509 * * *$ & 12.697 \\
\hline \multicolumn{2}{|c|}{ Level 2 (reef) variance } & $12.569 * * *$ & 0.927 \\
\hline \multicolumn{2}{|l|}{$-2 * \log$ likelihood } & 4447.873 & \\
\hline \multicolumn{2}{|l|}{$\mathrm{N}$} & 658 & \\
\hline
\end{tabular}

As expected, the presence of siltation and damage due to dynamite fishing at a coral reef site reduces the number of visitors to that site. Air temperature is also found to have a statistically significant negative effect on the number of visitors at a coral reef site. This indicates that additional increases in temperature reduce the attractiveness of recreation locations. An optimal temperature or possible non-linear effects with temperature were examined by including a quadratic term in the regression model, but no statistically significant effects were found. The estimated coefficient on the area of coral cover at the site is positive but not quite statistically significant at the $10 \%$ level. The area of mangroves within a $50 \mathrm{~km}$ radius of the coral reef site is found to have a positive and statistically significant effect on the number of visits. This suggests that there may be positive effects from the extent of other coastal ecosystems on the attractiveness of coral reef sites to visitors. This apparent complementarity between ecosystems possibly indicates the degree of naturalness of the site location. The size of the population living within a $50 \mathrm{~km}$ radius of a coral reef site is found to have a negative and statistically significant effect on the number of visitors. On one hand this result is somewhat surprising, since the population in the vicinity of a coral reef represents potential visitors.

On the other hand, visitors to coral reefs are often not local residents. This may particularly be the case in developing countries for which a large proportion of coral reef visitors are international tourists. In this respect, visitor models for coral reefs may differ substantially from visitor models for other ecosystems, for which the size and proximity of the local population are important explanatory factors (Sen et al. 2014).

The negative effect of population in the vicinity of a coral reef site is interpreted here as the pressure and impact of urbanization and other types of development on the attractiveness of a coral reef to visitors. The estimated coefficient on gross cell product (GCP), which is a spatially disaggregated 
measure of economic activity equivalent to gross domestic product (GDP), ${ }^{3}$ indicates that visitor rates are higher in regions with higher income levels. This variable does not necessarily represent the income of visitors themselves, given that visitors are often international tourists, but may reflect the availability and quality of infrastructure in a region. The estimated level 2 (reef-specific) variance indicates that there remains unexplained reef-specific variation in visitor numbers. Calculating the variance partition coefficient $[12.569 /(12.569+145.509)=0.08]$ shows that approximately $8 \%$ of residual variance in visitor numbers can be attributed to unobserved differences between reefs. ${ }^{4}$

\subsection{Meta-Analytic Value Function for Reef Recreation}

Following Brander et al. (2007) and Londoño and Johnston (2012), a meta-analysis of the coral reef valuation literature is used to estimate a value function for coral reef-related recreation. The coral reef value data set used to estimate value functions for coral reef ecosystem services is an extension of the data described in Brander et al. (2007). These data have been expanded to include a number of recent coral reef valuation studies. We restrict this data set, however, to select only estimates obtained using contingent valuation or travel cost methods in order to ensure the theoretical validity of the welfare estimates (e.g., we excluded estimates that measure gross revenues). The restricted sample size is 74 , of which 47 are contingent valuation estimates and 27 are travel cost estimates.

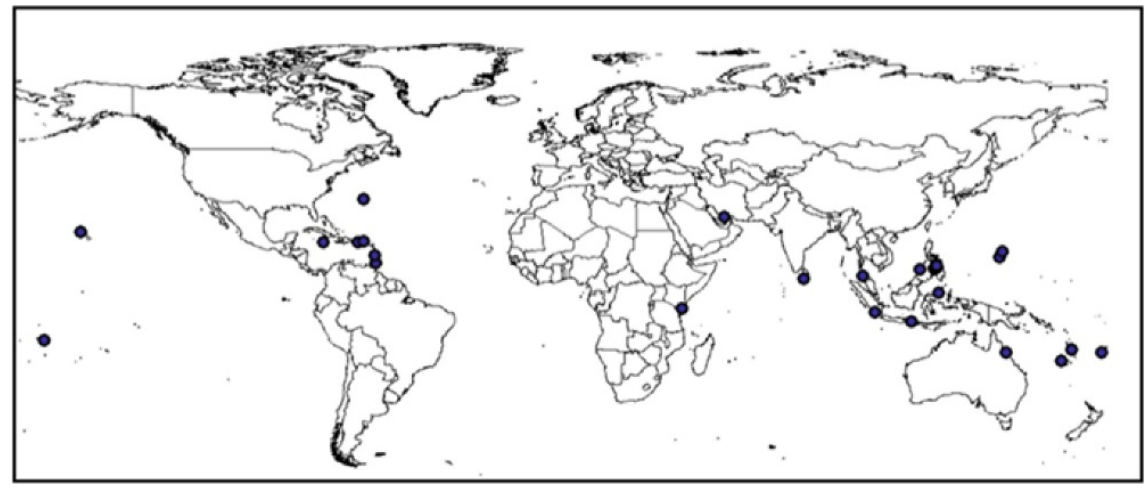

Figure 1: Location of coral reef recreation valuation study sites

The studies included in our analysis were published between the years 1992 and 2012. The geographic distribution of study sites is presented in Figure 1. Southeast Asia is reasonably well represented in the data with 13 valuation estimates (17\% of the sample). The locations of the remaining estimates are the Caribbean (16\%), the United States (51\%), ${ }^{5}$ Indian Ocean (13\%), and Australasia (3\%).

The data on the value of reef-related recreation are standardized to a common currency, year of value and units using Purchasing Power Parity (PPP) adjusted exchange rates and GDP deflators from the

\footnotetext{
${ }^{3}$ The conceptual basis of GCP is the same as GDP as developed in national income accounts. The basic measure of output is gross value added in a specific geographical region. Gross value added is defined as total production of market goods and services less purchases from other businesses. Under the principles of national economic accounting, GCP will aggregate up across all cells within a country to GDP (Nordhaus et al. 2006). This variable is correlated with population, but not perfectly.

${ }^{4}$ We test the influence of unobserved reef specific effects using a likelihood ratio test, for which the null hypothesis is that $\sigma_{\mu}^{2}=0$. We compare the estimated model with a model where $\sigma_{\mu}^{2}$ is constrained to equal zero, i.e., a single level model. The value of the likelihood ratio statistic is $5157.32-4447.87=709.442$. Comparing this to a chi-squared distribution on 1 degree of freedom, we conclude that there are significant unobserved differences between reef sites.

${ }^{5}$ Including Hawaii.
} 
World Bank World Development Indicators. ${ }^{6}$ The standardized values are expressed in US\$ per visitor day in 2007 prices. This is the dependent variable in the meta-analytic regression model. The model is given in the following equation:

$$
\ln \left(y_{i}\right)=\alpha+b_{S} X_{S i}+b_{R} X_{R i}+b_{M} X_{M i}+\mu_{i}
$$

The subscript $i$ assumes values from 1 to 74 (number of observations), $\alpha$ is the constant term, $b_{S}, b_{R}$ and $b_{M}$ are the coefficients of the explanatory variables and $\mu$ is a vector of residuals. The explanatory variables consist of three categories, giving characteristics of: (i) the study site $X_{S}$, (ii) the recreational activities valued $X_{R}$, and (iii) the valuation method used $X_{M}$. Table 3 presents the full list of variables included in the analysis, with the mean and standard deviation of each.

The meta-regression results are presented in Table 4. Following best practice, heteroskedasticityconsistent standard errors are estimated. However, the null hypothesis of homogenous variance of the residuals cannot be rejected by White's test for heteroskedasticity (White's statistic $=21.589$ ). The adjusted $\mathrm{R}^{2}$ statistic indicates that approximately $41 \%$ of the variation in the dependent variable is explained by the explanatory variables, which is comparable with similar meta-analyses of the ecosystem service valuation literature (e.g., Brander et al. 2007; Ghermandi et al. 2010).

Table 3: Variables included in the meta-analytic value function

\begin{tabular}{l|l|l|l}
\hline Variable & Variable definition & Mean & $\begin{array}{l}\text { Standard } \\
\text { deviation }\end{array}$ \\
\hline Value per visit & US\$ per visitor day & 73.86 & 171.66 \\
\hline Visits per day & Visits per day & 196.83 & 388.23 \\
\hline Area of coral cover & Area of coral cover $\left(\mathrm{km}^{2}\right)$ & 16.29 & 26.83 \\
\hline Caribbean & Dummy: $1=$ Caribbean; $0=$ other & 0.16 & 0.37 \\
\hline Indian Ocean & Dummy: $1=$ Indian Ocean; $0=$ other & 0.13 & 0.34 \\
\hline Southeast Asia & Dummy: $1=$ SE Asia; $0=$ other & 0.17 & 0.38 \\
\hline Australia & Dummy: $1=$ Australia; $0=$ other & 0.03 & 0.16 \\
\hline Diving & Dummy: $1=$ diving; $0=$ other & 0.77 & 0.42 \\
\hline Snorkelling & Dummy: $1=$ snorkelling; $0=$ other & 0.64 & 0.48 \\
\hline Fishing & Dummy: $1=$ fishing; $0=$ other & 0.07 & 0.25 \\
\hline CVM & $\begin{array}{l}\text { Dummy: } 1=\text { CVM; } 0=\text { other (travel cost } \\
\text { method) }\end{array}$ & 0.61 & 0.49 \\
\hline
\end{tabular}

\footnotetext{
${ }^{6}$ http://data.worldbank.org/data-catalog/world-development-indicators.
} 
Table 4: Estimated meta-analytic value function

\begin{tabular}{l|l|l|l}
\hline Variable & Variable definition & Coefficient & $\begin{array}{l}\text { Standard } \\
\text { error }\end{array}$ \\
\hline Constant & & $3.871^{* * *}$ & 1.087 \\
\hline Visits per day & Natural log of visits per day & $-0.434^{* *}$ & 0.174 \\
\hline Area of coral cover & Natural log of area of coral cover $\left(\mathrm{km}^{2}\right)$ & $0.451^{*}$ & 0.278 \\
\hline Caribbean & Dummy: $1=$ Caribbean; $0=$ other & $1.482^{* *}$ & 0.736 \\
\hline Indian Ocean & Dummy: $1=$ Indian Ocean; $0=$ other & $2.932^{* * *}$ & 0.943 \\
\hline Southeast Asia & Dummy: $1=$ Southeast Asia; $0=$ other & $1.456 *$ & 0.822 \\
\hline Australia & Dummy: $1=$ Australia; $0=$ other & 0.065 & 1.087 \\
\hline Diving & Dummy: $1=$ diving; $0=$ other & -0.276 & 0.476 \\
\hline Snorkelling & Dummy: $1=$ snorkelling; $0=$ other & $-0.980^{* *}$ & 0.446 \\
\hline Fishing & Dummy: $1=$ recreational fishing; $0=$ other & 0.131 & 0.491 \\
\hline CVM & $\begin{array}{l}\text { Dummy: } 1=\text { contingent valuation; } 0= \\
\text { other }\end{array}$ & $-1.949 * * *$ & 0.449 \\
\hline Adjusted R2 & 0.41 & & \\
\hline $\mathrm{N}$ & 74 & & \\
\hline$* p \leq 0.10, * * \leq 0.05, * * * p \leq 0.01$ & & \\
\hline
\end{tabular}

The estimated model broadly fits prior expectations. The estimated coefficient on the number of visitors to a reef has a negative sign and is statistically significant, suggesting that visitors prefer less crowded coral reefs. The area of coral cover has a positive effect on the welfare derived from a recreational visit. Visitors have a preference for coral reefs with larger areas. Regarding the results on the regional indicators, reefs in the Indian Ocean, Caribbean and Southeast Asia are all found to provide significantly higher recreational values than reefs in the U.S. (the omitted category in the set of regional dummy variables). The values of recreational visits to Australian reefs are not statistically significantly different from visits to U.S. reefs. Regarding the dummy variables indicating the principal recreational activity that is valued, only the estimated coefficient for snorkelling is statistically significant and indicates that the value of this activity is lower than for others. ${ }^{7}$

Regarding valuation methods, we find that contingent valuation (CVM) estimates are statistically significantly lower than estimates obtained using the travel cost (TCM) method. From a theoretical perspective we might expect CVM estimates to exceed TCM estimates, given that the former may include some element of nonuse value in addition to the direct use value of a recreational visit. On the other hand, TCM estimates for recreational visits that are part of a more complex multi-purpose trip, such as a vacation to a tropical island, may over-estimate the value of individual constituent activities (Armbrecht 2014). Empirical evidence with regard to the extent that these two methods produce similar results is somewhat ambiguous. Carson et al. (1996) review 83 valuation studies for quasi-public goods from which 616 comparisons of CVM and revealed preference (RP) estimates are made. The sample mean CVM/RP ratio is 0.89 , with a $95 \%$ confidence interval of $0.81-0.96$ and a median of 0.75 .

\footnotetext{
${ }^{7}$ The omitted category of reef-related recreation is a general category of "other" activities, including the viewing of coral reefs from boats. Our prior expectation is that the value of diving would be higher than other reef-related recreational activities. We do not, however, find evidence that the value of diving is different from recreational fishing or reef viewing. These activities can evidently also be of high recreational value.
} 
Although the results from this study show that RP methods produce higher value estimates than CVM, they also show that estimates from these two methods are within the same range. Mayor et al. (2007) compare TCM and CVM estimates specifically for recreational visits and find that the former tend to exceed the latter. Previous meta-analyses of the coral reef valuation literature have found similar results to those of the present study (Brander et al. 2007; Londoño and Johnston 2012).

\subsection{Data and Scenario for Coral Reef Loss, 2000 - 2050}

The next step in assessing the welfare change associated with the loss of coral reef area over the period $2000-2050$ is to develop a database of coral reef ecosystems in Southeast Asia that contains information on the variables included in the visitor model and the meta-analytic value function. We then develop a baseline scenario for the change in the spatial extent of coral reef ecosystems in Southeast Asia for the period 2000-2050.

Individual ecosystem or patch-level data on coral reefs in Southeast Asia were obtained from the UNEP World Conservation Monitoring Centre (WCMC, described in Giri et al. 2011). For each of the 5290 coral reef patches in Southeast Asia that are included in the UNEP-WCMC database, we used a GIS to obtain information on the area of each coral reef and area of mangroves, population and gross cell product within $50 \mathrm{~km}$.

We make use of the results of the Reefs at Risk Revisited assessment by the World Resources Institute (Burke et al. 2011) to define a baseline scenario for coral reef change for the period $2000-2050$. This assessment provides a spatially explicit projection of the degree to which coral reefs are threatened. The threats included in the Reefs at Risk Revisited assessment are coastal development, watershedbased pollution, marine-based pollution and damage, over fishing and destructive fishing, thermal stress and ocean acidification. These local and global threats are combined into an integrated index representing the degree to which coral reefs are threatened. Threat levels are classified as low, medium, high, very high, or critical. The proportion of coral reefs in the low-or medium-threat categories declines over time, whereas the proportion of coral reefs that are highly, very highly or critically threatened increases dramatically. We used spatially differentiated change factors derived from the Reefs at Risk Revisited integrated threat data, combined with the patch-level data on coral reefs from the UNEP-WCMC, to calculate the change in area of each patch of coral reef for the period $2000-2050$. The baseline loss of coral cover is presented in Figure 2. 


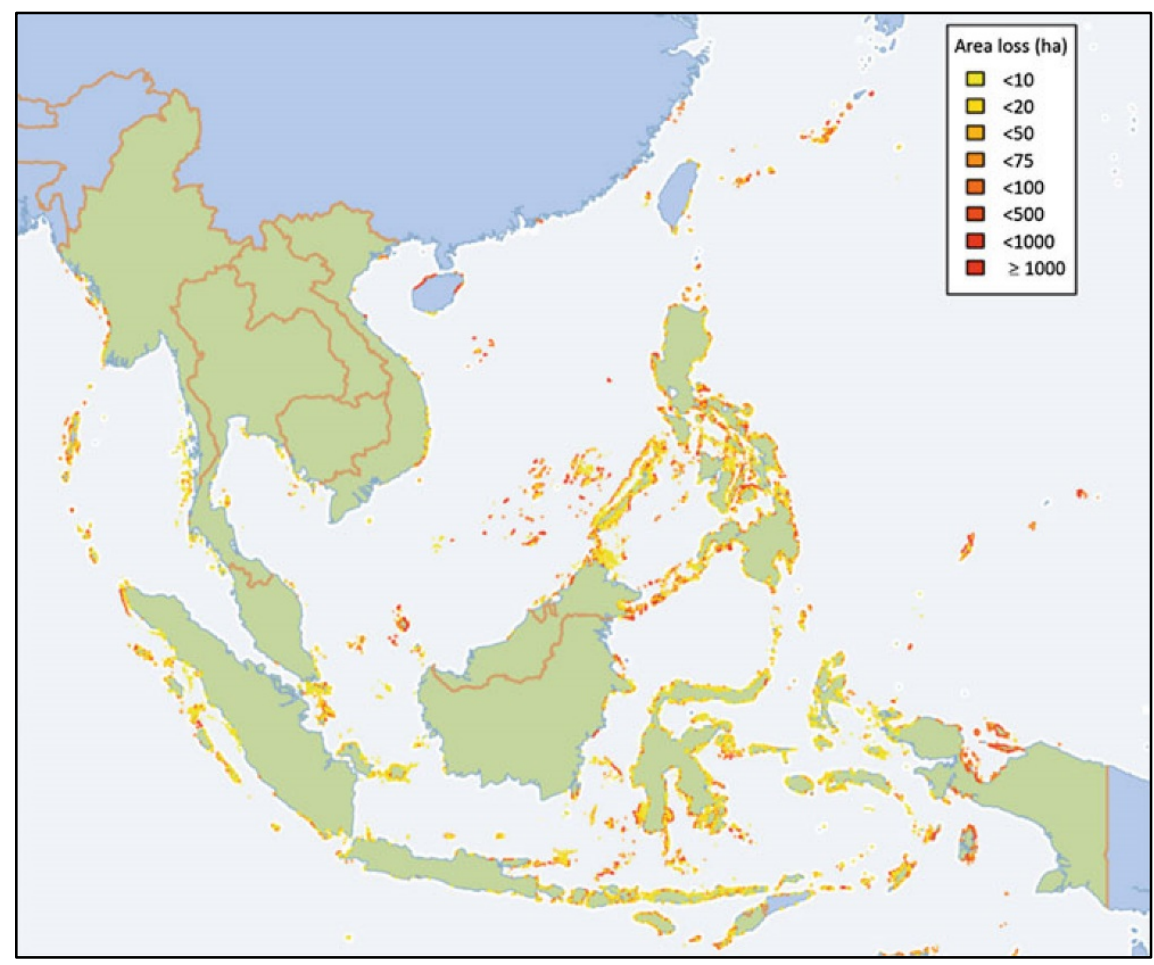

Figure 2: Change in area of coral cover 2000-2050 in Southeast Asia

\subsection{Results and Value Maps}

The final step in the assessment is to combine the models and data generated in the previous steps to produce estimates of the value of the loss in coral reef-related recreation under the baseline scenario.

At the level of individual patches of coral reef, patch-specific parameter values are substituted into the visitor model to estimate the number of visitors to each site. Visitor numbers are estimated for the year 2050 by using the areas of coral cover and mangroves existing in 2000 (i.e., under a conservation scenario) and the projected areas in 2050 (i.e., the baseline scenario). The difference between these two scenarios gives the estimated site-specific change in visitor numbers due to ecosystem degradation. The change in visitor numbers is represented in Figure 3 and is shown to be relatively insensitive to loss in coral cover. The average decrease in the annual visitation rate per site is only approximately 190 visitors. Nevertheless, there is substantial spatial variability across sites, due to both the underlying popularity of a site and the extent of change in the area of coral cover at that location. For example, the decrease in visitor numbers is shown to be higher for coral reefs on the east coast of Vietnam than for the west coast of Myanmar and Thailand. 


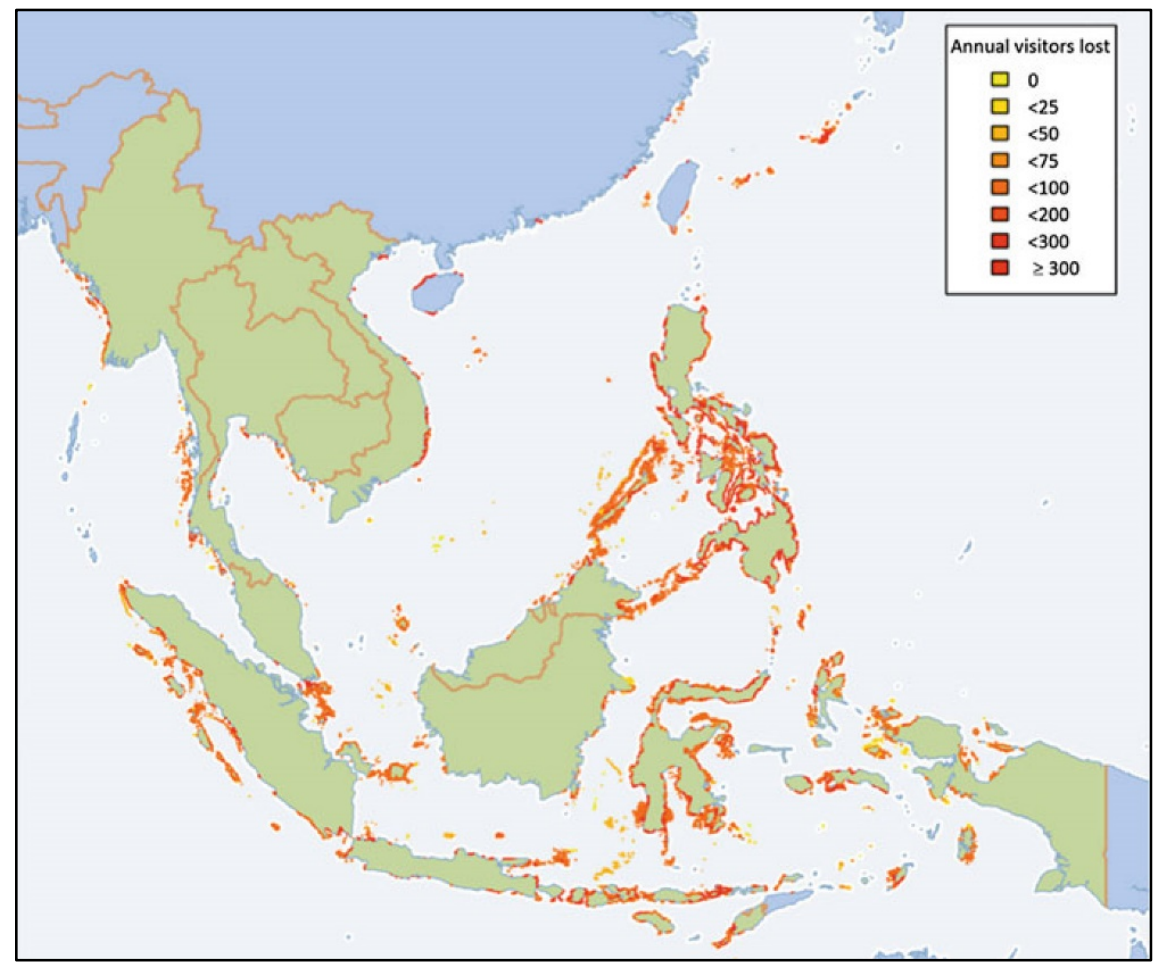

Figure 3: Change in coral reef-related recreation visits per day in Southeast Asia

The value per visit to each site is computed by substituting patch-specific parameter values into the meta-analytic value function. This is done using pre-and post-change areas of coral cover and visitor numbers in order to estimate the value of a visit to each site before and after ecosystem service degradation.

Two components of the change in welfare due to ecosystem degradation are then computed. The first component is the loss in consumer surplus associated with the decrease in the number of visitors. This is computed as the decrease in visitors at each site multiplied by the pre-change value per visitor (i.e., the loss in value to those that no longer visit). The second component is the loss in consumer surplus associated with the decrease in value of visits that still take place (i.e., visitors may continue to visit a site but derive lower utility per visit from doing so). This is computed as the decrease in value per visit at each site multiplied by the number of visitors under the degradation scenario. Lower-and upperbound values are calculated using the $95 \%$ prediction intervals for each coral reef, which are computed using the method proposed by Osborne (2000). The prediction intervals provide an indication of the precision with which the estimated value function can predict out-of-sample values. The results are presented in Figure 4 and in Table 5, aggregated to the country level. For Southeast Asia as a whole, the annual loss in consumer surplus from reef-related recreation in 2050 due to coral reef degradation is approximately US\$120 million (with a 95\% prediction interval of US\$ 3 million - 1.4 billion). The $95 \%$ prediction interval is very large and reflects the high uncertainty in estimating site-specific values per visitor day. The countries expected to suffer the highest losses are Indonesia and the Philippines, which have the largest areas of coral reef and numbers of reef-related recreational visits. There is considerable spatial variation in the change in value of reef-related recreation across sites reflecting differences in rates of coral cover loss, visitor numbers and values per visitor. 


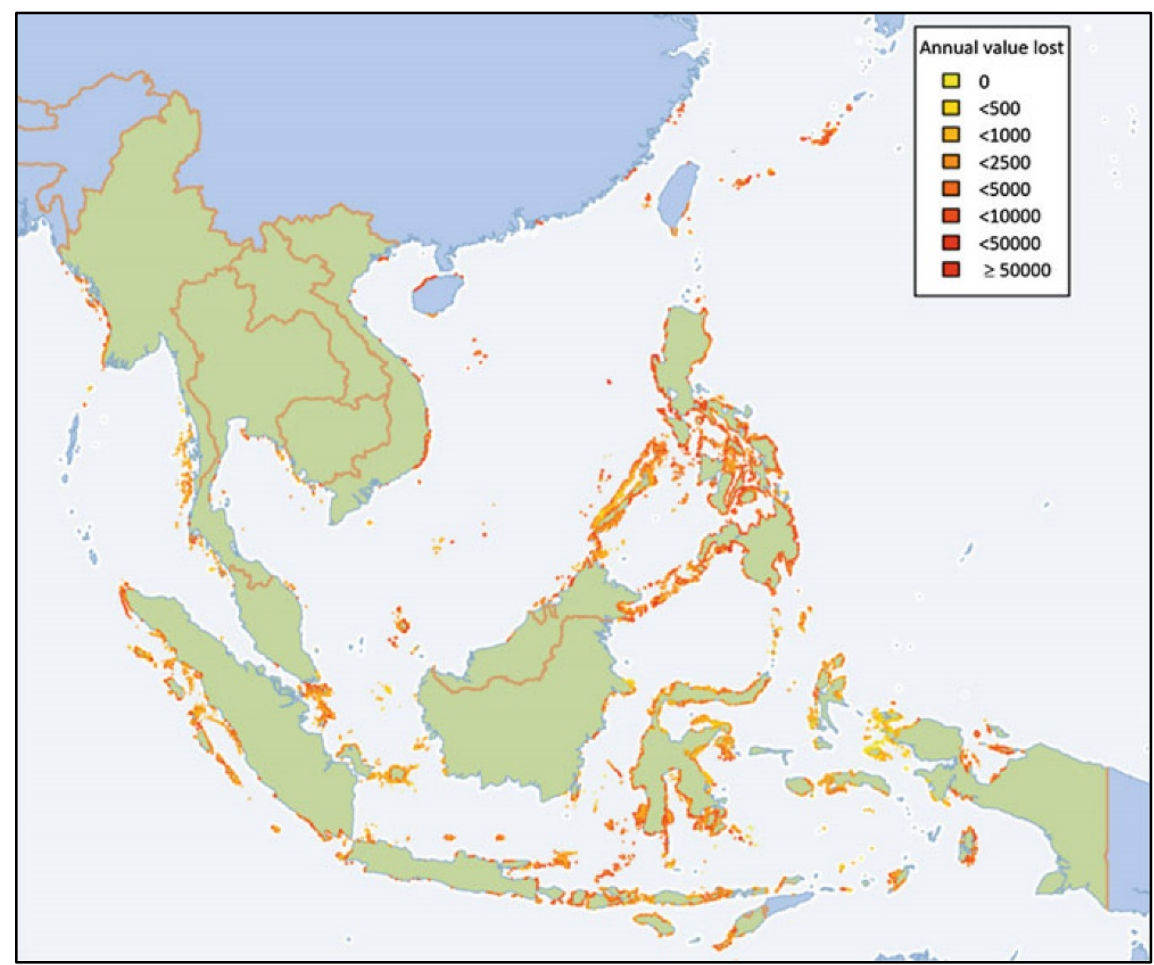

Figure 4: Loss in the annual value of coral reef-related recreation in 2050 due to policy inaction

Table 5: Change in consumer surplus of reef-related recreation in Southeast Asia caused by Ecosystem Degradation, 2050 (2007 US\$)

\begin{tabular}{l|l|l|l|l}
\hline Country & $\begin{array}{l}\text { Value per } \\
\text { visitor day }\end{array}$ & $\begin{array}{l}\text { Total change in } \\
\text { consumer surplus } \\
(\mathbf{0 0 0 s})\end{array}$ & $\begin{array}{l}\text { Lower bound 95\% } \\
\text { prediction interval } \\
(\mathbf{0 0 0 s})\end{array}$ & $\begin{array}{l}\text { Upper bound 95\% } \\
\text { prediction interval } \\
\text { (000s) }\end{array}$ \\
\hline Cambodia & 11.20 & -124 & 0 & -1392 \\
\hline Indonesia & 8.90 & $-59,468$ & -1099 & $-665,880$ \\
\hline Malaysia & 10.80 & -3140 & -280 & $-35,161$ \\
\hline Myanmar & 4.60 & -2836 & -253 & $-31,754$ \\
\hline Philippines & 6.50 & $-56,749$ & -5068 & $-635,440$ \\
\hline Singapore & 2.60 & -176 & -16 & -1972 \\
\hline Thailand & 5.80 & -1936 & -30 & $-21,680$ \\
\hline Vietnam & 4.00 & -3577 & -319 & $-40,058$ \\
\hline Southeast Asia & 6.80 & $-128,007$ & -2848 & $-1,433,337$ \\
\hline
\end{tabular}

It is important to note that the estimated welfare loss is only for the impact of coral reef degradation on the consumer surplus derived from reef-related recreation. The estimated values do not include producer surplus associated with reef-related recreation or impacts on other reef-related ecosystem services. The impacts on other ecosystem services provided by coral reefs, such as coastal protection and fisheries, are likely also to be substantial and possibly more sensitive to changes in coral cover.

\section{Conclusion}

This chapter illustrates the process of mapping ecosystem service values with an application to value changes in coral reef recreational values in Southeast Asia. This case study provides an estimate of the 
value of reef-related recreation foregone, caused by the decline in coral reef area in Southeast Asia under a baseline scenario of ecosystem degradation for the period 2000-2050. This value is estimated by combining a visitor model, meta-analytic value function and spatial data on individual coral reef ecosystems to produce site-specific values. The case study illustrates the data, methods and results of a value mapping exercise and allows several general conclusions to be drawn.

The estimated changes in visitors and values of reef-related recreation across Southeast Asia are not particularly high relative to their absolute values. Both visitation rates to coral reefs and values per visit are found to be relatively unresponsive to changes in the area of coral cover. ${ }^{8}$ The aggregated loss of consumer surplus derived from reef-related recreation due to ecosystem degradation under the baseline scenario is therefore limited. The central estimate of annual loss in 2050 of US\$ 128 million is not high, considering the size of the ecosystem providing the recreational services. The case study results do show, however, substantial spatial variation in the value of coral cover loss. This information can potentially be used in economic analyses for targeting conservation efforts to specific locations. With additional information on the spatial variability of conservation costs, a spatially explicit costbenefit analysis could be conducted to identify the location of conservation efforts in the region that would generate the highest returns. Such an analysis could be useful in locating new protected areas or planning new tourism developments.

There are several important limitations to the case study that are worth noting. There is a substantial challenge in obtaining reliable spatially disaggregated data on visitor numbers and characteristics with which to estimate a visitor model. The Reef Check data that we use in the case study application are focused primarily on the status of the reefs themselves, rather than on visitor numbers or visitor characteristics. We are therefore unable to include potentially important variables describing visitor characteristics in the model, such as recreational activity, income, origin and travel time. Future research should aim to collect such visitor-level data and include it in the estimation of visitor models. The lack of visitor-level data also restricts the options for including visitor characteristics in the metaanalytic value function, since it is necessary to have policy site data on each explanatory variable included in value function. Information on the income of visitors as a determinant of recreational value is again notably absent.

A second important limitation of the case study application is the restricted extent to which the supply of the ecosystem service is modelled. The supply side of reef-related recreation is essentially modelled implicitly in the visitor function, i.e., coral reefs supply recreational opportunities to the extent that people want to visit them. This approach may be defensible in the case of a cultural ecosystem service such as recreation, but still neglects other potentially important ecosystem characteristics that may determine the provision of the service, such as coral and fish diversity or water clarity. The method makes the analysis relatively simple but sidesteps the greater complexity involved in modelling the ecological functioning that underlies the supply of most ecosystem services. In general, accounting for spatial variability in ecosystem service values requires a closer integration of the bio-physical assessment of ecosystem services into the valuation of ecosystem services. The disconnection between these steps in the ecosystem service assessment process remains challenging; future applications should attempt to better combine ecological and economic modelling of the determinants of ecosystem service values.

Third, the analysis of visitor behavior and recreational value does not account for the potential impact of changes to substitute (or perhaps complement) sites. The current model treats each site as

\footnotetext{
${ }^{8}$ The regional mean proportional changes in visitor numbers and value per visit are -6 and $-12.5 \%$ for a $-27 \%$ change in the area of coral cover.
} 
independent, and does not allow for the possibility that simultaneous changes in the quality of multiple coral reef sites will influence visits and value in a way not captured through the aggregation of singlesite estimates. To the extent that these cross-site effects are relevant, estimates may depart from those reported here.

\section{References}

Armbrecht, J. (2014). 'Use value of cultural experiences: A comparison of contingent valuation and travel cost.' Tourism Management,. doi:10.1016/j.tourman.2013.11.010.

Bateman, I. J., Brainard, J. S. \& Lovett, A. A. (1995). 'Modelling woodland recreation demand using geographical information systems: A bene fi t transfer study (GEC 95-06).' Norwich, UK: University of East Anglia, Centre for Social and Economic Research on the Global Environment.

Bateman, I. J., \& Jones, A. P. (2003). 'Contrasting conventional with multi-level modelling approaches to meta-analysis: Expectation consistency in U.K woodland recreation values.' Land Economics, 79, $235-258$.

Bateman, I. J., Jones, A. P., Lovett, A. A., Lake, I. R., \& Day, B. H. (2002). 'Applying geographical information systems (GIS) to environmental and resource economics.' Environmental and Resource Economics, 22, $219-269$.

Bateman, I. J., Lovett, A. A., \& Brainard, J. S. (1999). 'Developing a methodology for bene fi t transfer using geographical information systems: Modelling demand for woodland recreation.' Regional Studies, 33, $191-205$.

Bockstael, N. E. (1996). 'Modelling economics and ecology: The importance of a spatial perspective.' American Journal of Agricultural Economics, 78, 1168 - 1180.

Brainard, J. S. (1999). 'Integrating geographical information systems into travel cost analysis and bene fi t transfer.' International Journal of Geographical Information Science, 13, 227 - 246.

Brander, L. M., Brauer, I., Gerdes, H., Ghermandi, A., Kuik, O., Markandya, A., et al. (2012). 'Using meta-analysis and GIS for value transfer and scaling up: Valuing climate change induced losses of European wetlands.' Environmental and Resource Economics, 52, 395 - 413.

Brander, L. M., van Beukering, P., \& Cesar, H. S. J. (2007). 'The recreational value of coral reefs: A meta-analysis.' Ecological Economics, 63, $209-218$.

Brouwer, R., Langford, I. H., Bateman, I. J., \& Turner, R. K. (1999). 'A meta-analysis of wetland contingent valuation studies.' Regional Environmental Change, 1, 47-57.

Burke, L., Reytar, K., Spalding, M., \& Perry, A. (Eds.). (2011). 'Reefs at risk revisited.' Washington, DC: World Resources Institute.

Carson, R. T., Flores, N. E., Martin, K. M., \& Wright, J. L. (1996). 'Contingent valuation and revealed preference methodologies: Comparing the estimates for quasi-public goods.' Land Economics, 72, 80 $-99$.

Cesar, H. S. J. (2000). 'Coral reefs: Their functions, threats and economic value.' In H. S. J. Cesar (Ed.), Collected essays on the economics of coral reefs (pp. 14-39). Sweden: Cordio.

Cesar, H. S. J., Burke, L., \& Pet-Soede, L. (2003). 'The economics of worldwide coral reef degradation.' The Netherlands: Cesar Environmental Economics Consulting, Arnhem and World Wildlife Fund, Zeist. 
Chen, N., Li, H., \& Wang, L. (2009). 'A GIS-based approach for mapping direct use value of ecosystem services at a county scale: Management implications.' Ecological Economics, 68, 2768- 2776.

Coiner, C., Wu, J., \& Polasky, S. (2001). 'Economic and environmental implications of alternative landscape designs in the Walnut Creek Watershed of lowa.' Ecological Economics, 38, $119-139$.

Costanza, R., d' Arge, R., de Groot, R., Farber, S., Grasso, M., Hannon, B., et al. (1997). 'The value of the world's ecosystem services and natural capital. Nature, 387, 253-260.

Costanza, R., Pérez-Maqueo, O., Martinez, M. L., Sutton, P., Anderson, S. J., \& Mulder, K. (2008). 'The value of coastal wetlands for hurricane protection.' Ambio, 37, $241-248$.

Crossman, N. D., Connor, J. D., Bryan, B. A., Summers, D. M., \& Ginnivan, J. (2010). 'Recon fi guring an irrigation landscape to improve provision of ecosystem services.' Ecological Economics, 69, 1031 1042.

de Groot, R., Alkemade, R., Braat, L., Hein, L., \& Willemen, L. (2010). 'Challenges in integrating the concept of ecosystem services and values in landscape planning, management and decision making.' Ecological Complexity, 7, 260-272.

Eade, J. D. O., \& Moran, D. (1996). 'Spatial economic valuation: Benefits transfer using geographical information systems.' Journal of Environmental Management, 48, 97 - 110.

Eigenbrod, F., Armsworth, P. R., Anderson, B. J., Heinemeyer, A., Gillings, S., Roy, D. B., et al. (2010). 'The impact of proxy-based methods on mapping the distribution of ecosystem services.' Journal of Applied Ecology, 47, $377-385$.

Ghermandi, A., \& Nunes, P. A. L. D. (2013). 'A global map of costal recreation values: Results from a spatially explicit meta-analysis.' Ecological Economics, 86, 1- 15.

Ghermandi, A., van den Bergh, J. C. J. M., Brander, L. M., de Groot, H. L. F., \& Nunes, P. A. L. D. (2010). 'Values of natural and human-made wetlands: A meta-analysis.' Water Resources Research, $46,1-12$.

Giri, C., Ochieng, E., Tieszen, L. L., Zhu, Z., Singh, A., Loveland, T., et al. (2011). 'Status and distribution of mangrove forests of the world using earth observation satellite data.' Global Ecology and Biogeography, 20, $154-159$.

Hein, L., van Koppen, K., de Groot, R. S., \& van lerland, E. C. (2006). 'Spatial scales, stakeholders and the valuation of ecosystem services.' Ecological Economics, 57, $209-228$.

Helian, L., Shilong, W., Guanglei, J., \& Ling, Z. (2011). 'Changes in land use and ecosystem service values in Jinan, China.' Energy Procedia, 5, 1109 - 1115.

Holzkämper, A., \& Seppelt, R. (2007). 'Evaluating cost-effectiveness of conservation management actions in an agricultural landscape on a regional scale.' Biological Conservation, 136, 117 - 127.

Londoño, L. M., \& Johnston, R. J. (2012). 'Enhancing the reliability of bene fi t transfer over heterogeneous sites: A meta-analysis of international coral reef values.' Ecological Economics, 78, 80 -89 .

Maes, J., Teller, A., Erhard, M., Liquete, C., Braat, L., \& Berry, P., et al. (2013). 'Mapping and assessment of ecosystems and their services: An analytical framework for ecosystem assessments under action 5 of the EU Biodiversity Strategy to 2020.' Luxembourg: Publications Office of the European Union. 
Mashayekhi, Z., Panahi, M., Karami, M., Khalighi, S., \& Malekian, A. (2010). 'Economic valuation of water storage function of forest ecosystems (case study: Zagros Forests, Iran).' Journal of Forestry Research, 21, $293-300$.

Mayor, K., Scott, S. \& Tol, R. S. J. (2007). 'Comparing the travel cost method and the contingent valuation method: An application of convergent validity theory to the recreational value of Irish forests.' Working Paper No. 190. Dublin: The Economic and Social Research Institute (ESRI).

MA (Millennium Ecosystem Assessment). (2005). 'Ecosystems and human well-being: General synthesis.' Washington, DC: Island Press.

Musa, G., \& Dimmock, K. (2012). 'Scuba diving tourism: Introduction to special issue.' Tourism in Marine Environments Special Issue, 8, 1-5.

Naidoo, R., \& Adamowicz, W. L. (2005). 'Economic benefits of biodiversity exceed costs of conservation at an African rainforest reserve.' Proceedings of the National Academy of Sciences of the United States of America, 102, $16712-16716$.

Naidoo, R., Balmford, A., Costanza, R., Fisher, B., Green, R. E., Lehner, B., et al. (2008). 'Global mapping of ecosystem services and conservation priorities.' Proceedings of the National Academy of Sciences, 105, $9495-9500$.

Nordhaus, W., Azam, Q., Corderi, D., Hood, K., Victor, N. M., \& Mohammed, M., et al. (2006). 'The GEcon database on gridded output: Methods and data.' Research Paper. New Haven, CT: Yale University.

Osborne, J. W. (2000). 'Prediction in multiple regression.' Practical Assessment Research and Evaluation, 7(2), 1 - 9. (ISSN 1531-7714).

Pet-Soede, L., Cesar, H. S. J., \& Pet, J. S. (2000). 'Blasting away: The economics of blastfishing on Indonesian coral reefs.' In H. S. J. Cesar (Ed.), Collected essays on the economics of coral reefs (pp. 77 -84). Sweden: Cordio.

Plummer, M. L. (2009). Assessing bene fi t transfer for the valuation of ecosystem services.' Frontiers in Ecology and the Environment, 7, 38 - 45.

Polasky, S., Nelson, E., Camm, J., Csuti, B., Fackler, P., Lonsdorf, E., et al. (2008). 'Where to put things? Spatial land management to sustain biodiversity and economic returns.' Biological Conservation, 141, $1505-1524$.

Rasbash J., Steele, F., Browne, W., \& Prosser, B. (2003). 'A user's guide to MLwiN version 2.0.' London: Centre for Multilevel Modelling, Institute of Education, University of London.

Schaafsma, M., Brouwer, R., Gilbert, A., van den Bergh, J. C. J. M., \& Wagtendonk, A. (2013). 'Estimation of distance-decay functions to account for substitution and spatial heterogeneity in stated preference research.' Land Economics, 89, 514 - 537.

Schaafsma, M., Brouwer, R., \& Rose, J. (2012). 'Directional heterogeneity in WTP models for environmental valuation.' Ecological Economics, 79, $21-31$.

Schägner, J. P., Brander, L. M., Maes, J., \& Hartje, V. (2013). 'Mapping ecosystem services' values: Current practice and future prospects.' Ecosystem Services, 4, 33-46.

Sen, A., Harwood, A. R., Bateman, I. J., Munday, P., Crowe, A., Brander, L. M., et al. (2014). 'Economic assessment of the recreational value of ecosystems: Methodological development and national and local application.' Environmental and Resource Economics, 57, $233-249$. 
Simonit, S., \& Perrings, C. (2011). 'Sustainability and the value of the regulating services: Wetlands and water quality in Lake Victoria.' Ecological Economics, 70, 1189 - 1199.

TEEB. (2010). 'The economics of ecosystems and biodiversity: Ecological and economic foundations.' London: Earthscan.

Troy, A., \& Wilson, M. A. (2006). 'Mapping ecosystem services: Practical challenges and opportunities in linking GIS and value transfer.' Ecological Economics, 60, $435-449$.

UK, N. E. A. (2011). 'UK national ecosystem assessment: Understanding nature's value to society: Synthesis of the key findings.' Cambridge: UK National Ecosystem Assessment.

UNEP (United Nations Environment Programme) (2006). 'Marine and coastal ecosystems and human well-being: Synthesis based on the findings of the millennium ecosystem assessment.' Nairobi: United Nations Environment Programme.

Van Beukering, P., Brander, L., Tompkins, E. \& McKenzie, E. (2007). 'Valuing the environment in small islands: An environmental economics toolkit.' Peterborough, UK: Joint Nature Conservation Committee (JNCC).

Veron, J. E. N., Hoegh-Guldberg, O., Lenton, T. M., Lough, J. M., Obura, D. O., Pearce-Kelly, P., et al. (2009). 'The coral reef crisis: The critical importance of $<350$ ppm CO 2.' Marine Pollution Bulletin, 58, $1428-1436$.

WTTC. (2013). 'Travel and tourism economic impact 2013: Southeast Asia.' London: World Tourism and Travel Council.

Zhang, M., Zhang, C., Wang, K., Yue, Y., Xiangkun, Q., \& Feide, F. (2011). 'Spatiotemporal variation of Karst ecosystem service values and its correlation and its correlation with environmental factors in Northwest Guangxi China.' Environmental Management, 48, 1-12. 